\title{
Keeping up with ELF: An Analysis of Erasmus Students' Attitudes
}

\author{
Nikola Jokic a * \\ a Institute of English Studies, Heinrichstraße 36, Graz, 8010, Austria
}

Received 30 January 2019 | Received in revised form 09 June 2019 | Accepted 18 July 2019

\begin{abstract}
APA Citation:
Jokic, N. (2019). Keeping up with ELF: An analysis of Erasmus students' attitudes. Eurasian Journal of Applied Linguistics, 5(2), 239-253. Doi: 10.32601/ejal.599244
\end{abstract}

\begin{abstract}
The aim of this paper is to give an insight into the perspectives of Erasmus students. The focus is on their experience, in particular, and how and to what degree ELF speakers in the study became accustomed to a new educational environment, and whether any obstacles materialised in the process. The goal is to demonstrate the significance of ELF-awareness and the role of English in this particular speech community. Qualitative methods were deployed to obtain the research results i.e. semistructured, informal ELF conversations between Erasmus exchange students at a university in Austria were tape-recorded and transcribed accordingly. During the interviews, students were asked questions about English as spoken at the university, and were instructed to compare and contrast the experiences gained at a university in Austria with those at their primary universities of instruction. The analysis will show the extent to which a new surrounding can influence the attitudes of Erasmus students.
\end{abstract}

(C) 2019 EJAL \& the Authors. Published by Eurasian Journal of Applied Linguistics (EJAL). This is an open-access article distributed under the terms and conditions of the Creative Commons Attribution license (CC BY-NC-ND) (http://creativecommons.org/licenses/by-nc-nd/4.0/).

Keywords: English as a lingua franca; Erasmus students; language attitudes

\section{Introduction}

\subsection{English and higher education}

The global status and dominant position of English is already explained in numerous articles and books regarding this topic. A particular aspect of this, and a more recent development, is the leading role of English in institutions of higher education where it is used predominantly for teaching and publishing purposes, but also because it serves as a medium of communication between non-native speakers of English. Graddol (2006) points out that "between 2 and 3 million students each year travel to another country to study" (p. 76) and that over half are taught in English. Despite the fact that the number of international students and academics has risen in

\footnotetext{
* Corresponding author.

E-mail address: nikola.jokic@uni-graz.at
} 
recent times, the lack of research is still a continuing concern within the framework of understanding the movement of people across borders (Findlay, 2011).

Even though universities in the Netherlands and Sweden began teaching in English in the 1950s, in other parts of Europe it took until the 1990s for the tide to begin to turn (Coleman, 2006, p. 6). The past decade has seen a growing number of universities offer an increasing range of English medium of instruction for a variety of programs at both undergraduate and postgraduate levels that contribute to greater student mobility. Ferguson (2007) draws our attention to the fact that most universities in mainland Europe introduced English as a medium of instruction as a means "to attract fee-paying international students, to enhance the university's international prestige and contacts and to develop the English language skills of their staff and students" (p. 13). Similarly, Coleman (2006) discusses the economic value of higher education and emphasizes that "the student has become the customer", while universities serve not as "institutions but brands" (p. 3).

At the same time as university policies were changing, exchange programs were initiated. The European Commission breathed life into the Erasmus programs in order to promote European integration. Further consequences have been internationalization and mobility of students in higher education. The effect of the latter can be seen in the increasing use of English, not just in the classroom, but between international students or as a medium for communication with even domestic native students. Thus, English "is used as a vehicular language by nonnative speakers of English to achieve communicative goals" (Jokic, 2017). Furthermore, by using English and participating in the process of internationalization, international students might considerably stand out in the job market, when compared to local students, by virtue of their migration and adaptation to the new environment (Truchot, 2002, p. 9).

The present paper seeks to estimate the extent to which English as a lingua franca (ELF) is used in an Erasmus community by taking into account students' subjective perceptions. Firstly, it mentions briefly the term ELF and international students' context. Secondly, it describes the methodology employed. Finally, the paper provides an in-depth analysis of the results and makes use of examples from the corpus in order to draw conclusions.

\subsection{English as a lingua franca context}

English as a lingua franca has been thoroughly described in the literature (Jenkins, 2000; Mauranen \& Ranta, 2009; Seidlhofer, 2011). The conclusion that has been reached finds misunderstandings to be a rare occurrence due to the "effort ELF users put in so as to prevent such problems" (Jokic, 2017). This contrasts the popular belief that the variety of different accents and levels of proficiency could lead to a breakdown in communication. Previous studies have reported the significance of ELF in academia (Björkman, 2011, 2013; Jenkins, 2000; Mauranen, 2010; Smit, 2010). Yet, what remains unexplored is international students' attitudes and perceptions toward 
English. Mauranen (2007) described the context of ELF as "a hybrid of many backgrounds" (p. 244) which would be the most accurate description of an Erasmus community where one is able to encounter individuals with different first languages, diverse nationalities and cultures.

As far as the international community is concerned, statistics on the website of this particular university in Austria reveal that in the winter semester of 2015/16 there were approximately 30,000 students, of which international students accounted for 14,43 percent. In the summer semester of academic year of 2015/16, the number of students attending the university was slightly below 30,000, however, the percentage of international students rose to 15,02 percent. According to this data and the fact that German is still the dominant language of instruction, this university is more suitably described as a national than a global university (Penz, 2015, p. 58). Furthermore, Penz (2015) reports that the range of courses taught in English is rather limited and that English and American Studies represents the sole degree programme "where the official language of teaching is English" (p. 59). By contrast, other universities in the same city (Technical University) effected the decision to implement English as the main language of instruction from the winter semester of 2014/15 (Penz, 2015, p. 56).

Although the range of English-taught courses is not broad, it is interesting to enquire after the manner in which international students come to cope with academic, linguistic and cultural challenges. In the section that follows, a description of the methodology is presented.

\section{Data and methodology}

The main goal is to understand the complex nature of English as a lingua franca and to discover whether the attitudes toward it are favourable. Another point is to determine how a new academic environment may have a bearing on these attitudes. The results of this study should provide further insights into the ELF phenomenon.

The data used for this study comprises seventeen sessions amounting to approximately 15 hours of tape-recorded ELF speech. This study involved the participation of Erasmus exchange students who studied at a university in Austria in the winter semester of $2015 / 16$. The students' lengths of stay ranged from six months to one year. The interviews lasted approximately forty-five minutes to one hour and included two to five participants, excluding the researcher. In terms of gender, fourteen participants were male and twenty-five female. All of the participants were non-native speakers of English ranging from age twenty to twenty- eight. As far as their linguacultural backgrounds are concerned, the study included eighteen different L1s of which the Romance group of languages represented the majority. This was followed by the Slavic, Germanic, Hellenic and Finno-Ugric languages (table 1). The participants' English proficiency skills ranged from intermediate to advanced. 
Table 1: The number and distribution of the participants based on their gender and the country of origin

\begin{tabular}{lll}
\hline COUNTRY & NUMBER & GENDER \\
\hline BELGIUM & 1 & $\mathrm{M}$ \\
BOSNIA AND HERZEGOVINA & 1 & $\mathrm{~F}$ \\
BRAZIL & 2 & $\mathrm{FF}$ \\
CROATIA & 9 & MMMMFFFFF \\
CZECH REPUBLIC & 1 & $\mathrm{~F}$ \\
FINLAND & 1 & $\mathrm{M}$ \\
FRANCE & 1 & $\mathrm{M}$ \\
GREECE & 1 & $\mathrm{M}$ \\
HUNGARY & 1 & $\mathrm{~F}$ \\
ITALY & 5 & $\mathrm{FFFMM}$ \\
NETHERLANDS & 1 & $\mathrm{~F}$ \\
NORWAY & 1 & $\mathrm{M}$ \\
PORTUGAL & 4 & MFFF \\
SERBIA & 1 & $\mathrm{~F}$ \\
SLOVENIA & 1 & $\mathrm{~F}$ \\
SPAIN & 6 & $\mathrm{FFFFFM}$ \\
SWEDEN & 1 & $\mathrm{M}$ \\
UKRAINE & 1 & $\mathrm{~F}$ \\
\hline
\end{tabular}

This study represents only a small part of a larger investigation into the communicative strategies used by ELF speakers. A semi-structured interview was determined as the best method to adopt. The questions though prepared in advance did not prevent the researcher from acting spontaneously to explore further themes or topics as they arose. The interviews were conducted in English with the presence of the researcher. For the purpose of analysis, examples that refer to the students' experience and corresponding research questions were taken from the data, examined thoroughly and then categorized as either positive or negative. The interactions were transcribed with the help of the VoiceScribe editor and using adapted VOICE markup and spelling transcription conventions.

In order to, on the one hand, better understand the attitudes of Erasmus students toward English spoken in a multilingual environment and on the other hand, explore their academic experience, a series of questions were posed. The inquiries relating to the educational matters involved mainly the comparison of practices between their primary university of higher education and a university in Austria, whereas the second subset of questions focused on the English Erasmus students used in conversation with one other. Therefore, the following research questions were framed so as to tackle the attitudes of Erasmus students:

1. What is the attitude toward English in everyday Erasmus students' interactions? 
2. Did the use of English lead to any misunderstandings?

3. How has student mobility influenced academic performance?

4. To what degree did Erasmus students adapt to the new educational environment and what, if any, obstacles were encountered in the process?

\section{Results}

\subsection{Experience with the English language}

The first set of questions dealt with the attitudes of international students toward the English language. They commented on the way exchange students use English which was followed by questions about potential misunderstandings in communication.

As regards English, the response was mixed. When the participants were asked to say what they thought of its usage, the majority stated that they did not experience any problems in interaction, however, they singled out the pronunciation of certain languages as one of the factors that could have influenced the way those students spoke English.

\section{Example 1:}

S1: yeah what do you think about the english being used among errr erasmus students do you understand them do you has it often happened to you that in the conversation err misunderstandings often occur

S3: never occurred i think eerr

S1: is it eas

S3: every erasmus $\mathrm{xxx}$ can communicate with each other like very easily

.....

S3: sometime s really hard sometimes then they go xxxxxx words not from you because your english is very good but that there is some people that have like a very strong accent spanish people have strong ase accent

Example 2:

S2: $<1>$ i have people $</ 1>$ with problems issues with people speaking english for example from vietnam

S3: yeah i agree i agree $<2>$ i agree $</ 2>$

S2: $<2>$ because their $</ 2>$ pronunciation is flat

S3: i did a project for a computer science with this egyptian guy and he it was horrible i i could barely understand him like he uses a lot of $i$ think they are glottal sounds

The explanation might lie in the fact that the majority of Erasmus students do not imitate native speakers of English pronunciation patterns but rather speak in English that is shaped by their L2 and are, therefore, more focused on getting their message across.

Furthermore, there were those who thought that the English of Erasmus students is quite limited and not that sophisticated. These comments were not very frequent, but they provide important insights into the function of English among students. This could be particularly seen in the following example: 
Example 3:

S2: it's very poor they because like students erasmus students they use english just tsss you know it's not the beautiful english which you want to hear all the time and just english which you use to understand each other like pass me a beer or something like that you know like

$\mathrm{S} 1: \mathrm{mhm}$

S2: it's not really deep and nice language so that is what i would call it

Example 4:

S3: $i$ hate it i hate it so much

S1: why

S3: as i said before

S3: $<1>$ yeah $</ 1>$ but of usually it works fine but i still find it to be a problem because (.)

it prevents people from learning other languages

Despite expressing his/her animosity toward the use of English among students, the participant in Example 4 highlights one more disadvantage of ELF, which is the inability to learn other languages due to the practicality of using English. It is possible, therefore, that some students had a preconceived notion of a 'beautiful and deep' English which did not fulfil their expectations and further led to an obstacle to learning the language of the country.

Apart from commenting on Erasmus English used in this Austrian city, a recurrent theme about Austrian English emerged from the analysis. What was striking was that the majority of those who responded to this question felt that they were undecided as to whether Austrian English was good enough as far as the language skills are concerned. A small number of respondents indicated that it portrayed a wide variety of grammar constructions and vocabulary while some participants expressed the belief that English spoken by Austrians was significantly low-level and below the standard.

Example 5:

S2: $<2>$ also $\mathrm{i}</ 2>$ have seen they have problems to understand english many of them $<3>$ but that what $\mathrm{s}$ make $</ 3>$

S3: $<3>$ uuuu $</ 3>$ maybe depends i don't know

S2: $<4>$ because i was having $</ 4>$

S3: $<4>$ i don't i have it $</ 4>$

S2: i was during the lesson some lesson so i was mixing i was mixed with austrians in the university

S3: $\mathrm{mhm}$

S2: and i find out that $<1>$ sometimes $</ 1>$

S3: $<1>$ on $\mathrm{TU}</ 1>$

S2: sometimes

S3: yeah

S2: sometimes their own english skills are quite low

S3: yeah sometimes they are but $i$ think a lot of them knows decent english

S3: and some of the like i took mostly english classes and the people because i don't speak german so the people understood english they were okay with it their pronunciation wasn't that good but that s i mean that s normal everyone (.) has to have like an accent so 
Example 6:

S2: i think i found really two opposite situation there's people that speaks really good english

S1: $\mathrm{mhm}$

S2: and pe people that don't have a clue about english

$\mathrm{S} 1: \mathrm{mhm}$

S2: up to now it's really difficult to find somebody which is in the middle

These differences can be explained in part by the fact that some Austrians, whether they are students or not, did not have a lot of contact with the English language in their daily use; or even if they did, they did not want to master it. Therefore, the apparent lack of advanced structures and phrases could be attributed either to education or the conscious wish not to utilize it.

This discussion triggered another theme that came up in the interviews. The students made a distinction between particular settings where English was used, namely the university and other public places in the city. The great majority said that they only spoke English around the university and that as soon as one stepped out of the campus, one could notice the difference;

Example 7:

S3: i agree with that errr and xxx also in offices and err other public places there are people who are completely ignoring english completely cannot speak any word of english and just smiling at you and saying try to some to speak with some other guy or to to find solution but and other that are really really good

S1: but could you say that $\mathrm{xxx}$ is an international place

S3: well maybe $<1>$ errrrrr yee $x x x$ the university yeah $</ 1>$

S2: $<1>i$ think it depends inside the university $\mathbf{i}$ think $</ 1>$ yes it is true in the university there is a lot students from different countries but as far as i can see if you go it is limited so the university does not really mirror the society and xxx outside

The answer for this huge discrepancy could be found in the fact that English is the most widely used language among international students. Therefore, it should come as no surprise that it is on the university grounds it is heard the most. However, the international students who chose this city as a part of their Erasmus experience expected it to be more internationally (English)-oriented due to its number of younger student population that is expected to speak English. Similarly, in their accounts they reported on being shocked that in the center of the city and in public places there were no speakers of English, which made it almost impossible for them to get by, especially if they were not familiar with the German language.

Example 8:

S2: ....there is a huge difference in in depending on the place you live in xxx so if you live in the center people speak English if you go outside like to different districts poor districts they don't speak English at all and even in the center they all not not all of them speak english like for example the people working at spar they don't and the shoe shops either neither not and $<1>\mathrm{xxxx}</ 1>$

S3: people $<1>$ that even work $<1>$ at this dorm don't know how to speak English 
S2: yeah they $<1>$ always send me messages in German $<1>$

S3: $<1>$ the cleaning ladies $<1>$

S2: and yes i i am learning german i know i have to learn german but you also should speak because i xxx say that Spanish people should speak English

S3: the place where you are supposed to arrange public transportation pass they don't speak English which I don't find it normal I was lucky to go with a friend that speaks German so she helped me otherwise I wouldn't understand anything that the woman wanted to tell me

As far as misunderstandings are concerned, a common view amongst interviewees was that it was far easier to understand non-native speakers of English than native speakers due to the lack of idiomaticity use or particular regional pronunciation of native speakers of English.

Example 9:

S2: yeah that is true aaa $\mathbf{i}$ think it depends of the native speaker in general north americans are easier to understand i think

S1: $\mathrm{mhm}$

S2: the british accent is $\operatorname{xxxx}$ but yeah but that $\mathrm{s}$ really true umm between non natives it is always easier

S3: yeah also for me

\section{Example 10:}

S2: i guess sometimes okay maybe australians i don't understand them $<1>$ that well $<1>$

S3: $<1>\mathrm{xxxx}</ 1>\mathrm{xxx}$ mate

S2: but you know like for some $\operatorname{xxxxxx}$ like to i mean on some party some small talks it is maybe better to talk with non native speakers because you don't feel ashamed because of your accent

S1: $\mathrm{mhm}$

S2: and also use the words which all over the foreigners learn in school you know like they don't use that sophisticated

S3: kind of the same i think if you if the dialect of english is is a bit a bad to understand for example like some southern american us american us american $<1>$ lang $</ 1>$

S1: $<1>$ texas $</ 1>$

S3: yeah they real they mumble a bit the the words so they are pretty difficult to understand or also australian ummm but also i think it is we are pretty the same if it is $\operatorname{xxxxx}$

Apart from stressing that it is hard for them to understand the pronunciation of Australians and maybe southern Americans, some of the respondents indicated that the reason why talking to non-native English speakers is more appealing is because there is no one to judge their accent. Interestingly, the speaker in Example 10 goes on to say that by using less sophisticated English helped him/her feel less threatened.

Talking about misunderstandings an interviewee said:

Example 11:

S2: especially like it is it is really funny because like e english it is like a neutrum umm language i mean umm everybody okay speaks english but some expressions in my in my language so if if $i$ translate to to english it makes no sense S1: $\mathrm{mhm}$ 
S2: but i mean umm some situation or i tried like i tried to explain in a portuguese way or in a brazilian way aaaa did really not sound really good or i don't know but could sound in a in a different sense so i would yeah i had some misunderstandings like a bit with some expressions and so on but yeah everything was okay

In the extract above the respondent was trying to express that translating from their own source languages often led to humorous effect; however, the aim in the conversation was achieved without any breakdowns.

The interviews uncovered one particular and interesting example in which two people whose common language is Portuguese had no problem to communicate in English when other international students were around. However, in the situation in which there were two people of Swedish origin, problems arose.

Example 12:

S3: yeah i dont think that everybody like has this culture/ like to include everybody in the conversation

.....

S2: me me and ingrid we both speak portuguese and we always speak in english

S3: yeah we always speak in english

\section{Example 13:}

S3: you know i met a swedish guy yesterday $<1>$ for the $</ 1>$

S2: $<1>$ yeah $</ 1>$

S3: first time not the first swedish person i met but i i met this guy for the first time

S2: $\mathrm{mhm}$

S3: and i was errr out in this pub with marcel one of my friends from germany

$\mathrm{S} 2: \mathrm{mhm}$

S3: and we are always speaking german to one another and then i spoke a few sentences of swedish to the swedish guy and introduced myself and then i switched back to german again and he was offended

S1: $<1>$ did he $</ 1>$

S3: $<1>$ i am $</ 1>$ swedish and you are speaking german with me why@@

S1: did he did he tell you that

S3: yes

The answer may potentially be sought in different cultures or interpersonal feeling speakers have toward speaking their own native language with a member of the same linguistic community. This discrepancy in attitudes could also be attributed to their exposure to the English language or the use of English as a medium of instruction, while on the other hand the reason for choosing not to participate in a conversation by using a foreign language may be owing to the lack of knowledge, comfort, or even national pride. Nevertheless, since there were just two examples in my data it would not be practical to draw a conclusion and generalize but merely to point out that the occurrence of such a tendency appears in international interactions.

\subsection{Academic settings}


In terms of academic settings, Erasmus students were asked to report on the culture of their host and primary university of instruction. Comments about the host university were more often negative than positive. In comparison to their home institutions and other experiences abroad, students perceived a greater lack of organization in courses. In addition, they experienced a lack of support in orientating themselves in the new academic environment, including the expectation to choose courses without the advice of those potentially knowledgeable in the subject matter.

The following examples are indicative:

Example 14:

S4: <1>it's very $<1>$ complicated to choose your course to organize it it is a it's a big mess every because you have when you see at the first time your timetable you can complicated to follow every courses and i I think it's only bad points are bureaucracy of the and the organization of the course of the university

Example 15:

S2: organization like you said before it's not that good I think it's more like free arrange it yourself do everything yourself

Example 16:

S3: ohhhhh i think here the university is really messy is everything is so confusing you have like you have to choose your courses and they are on different weeks and different days and different times and i have like all my classes are overlapping all the time

A possible explanation for these results may be the lack of coordination between institutes and guidance which is why many students do not succeed in maintaining the necessary rootedness in their field.

Example 17:

S3: i feel like here we have like a better selection of courses which is good but then also it's bad because like you don't have any structure you can basically choose whatever you want and in croatia you get a list of courses that you have to take that year and you're already enrolled you don't have to enroll on your own

S2: to that and here you have maybe you study more what you want or what you feel like 
S3: because i feel like here like people who study for example english took take a lot of courses from majors that are not connected to their majors so like philosophy or i don't know environmental studies because it can just get them the ects points.

This result may be explained by the fact that the curricula at this Austrian university offer students a wide variety of elective courses from which to obtain necessary ECTS points while other respective universities may prefer to adhere to compulsory courses.

Another issue that arose is related to examinations; traditionally scheduled in the last working week of the semester at this Austrian university, the experience of unusual and intensity was heightened, especially for those who were unaccustomed to this practice.

\section{Example 18:}

S3: i feel like this system is also from for people who start studying here but for people like us who just come from for one year i think it can be problematic because of the exam dates as well because $i$ had the last 2 weeks $i$ had all of my exams so i think i have 11 of them or something like that and it was really really stressful and in croatia that can't happen because they like evenly distribute everything

Example 19:

S3: they have the different concept of exam i mean@@err in italy we have classes till for example for the summer semester we have classes till middle may and then we have all the exams so here they continue with classes till the week before exam and this is so strange for me because you dont have the time to study

However, not all feedback on the institutional culture was negative. On the other end of the spectrum, a minority of participants suggested that the university offered them a variety of courses from which to choose, including both practice-based teaching formats, which implemented the theory through projects, as well as interactive approaches. This was seen as an opportunity for students to practice the knowledge acquired at their home university.

Example 20:

S2: you can see the difference because for example one course in Zagreb here is three courses that concentrates on three different subjects which is really great and I'm doing a lot of things

\section{Example 21:}

S2: yeah me too it is especially the seminar courses are more practical

S4: $<1>$ yeah $</ 1>$

S2: $<1>$ you learn $</ 1>$ a lot /at the/ short time

S3: yeah

S2: and i don't have it in my coun $<1>\operatorname{try}</ 1>$

$\mathrm{S} 4:<1>$ it is $</ 1>$ it's more interactive in seminar

S2: yeah

S4: you can you can more practice your your

S3: /with/ knowledge 
Furthermore, some participants highlighted the quality of delivering the courses as strength of the institution.

Example 22:

S2: it is different from Barcelona or Saragosa (spanish) in that professors make make classes mmm out of the students opinions whatever they come to class and they they they make questions they don't explain anything they wait for us to say something and that is all and in Spain it's not like that like we barely speak in class it's all about the professor the professors know everything they explain everything they are right and they tell us what to what we have to study that's it here is more open

\section{Example 23:}

S3: ... they have a lot of courses they are really fun and useful at the same time so that was that was a positive experience for me

A recurring theme in the dataset was the relationship between students and professors. Compared to other universities, students remarked on the familiarity between students and faculty. The majority of those who responded to this question described the relationship as friendly and close, even more so than in their home country. However, there were some instances in which the respondents reported that the manner of addressing professors felt unusual since this was not the custom at their home universities.

Example 24:

S2: I've already been to a bar with professor from the seminars they just after /that day/ come for a drink so

......

S3: yeah they are very friend here

S4: yes

Example 25:

S4: mhm i think the the shocking thing for me was my first like it classes like all the teachers told us to call them by their first name

S3: really

S2: okay that is a little bit weird

This could be attributed to differences in academic cultures. Some professors prefer to use a more informal and direct approach which postulates that everyone should be treated in the same way. Contrariwise, there are cultures that value a formal approach based on hierarchy.

Moreover, students felt that professors were sympathetic to their issues, and attempted to help them in any way possible. Interestingly, the assistance provided seems to some students to be due to their status as international students.

Example 26:

S2: it's closer here

S3: yeah it's closer but I think they always try to figure it out I mean I think they're nicer because we we are erasmus students 
S2: $<1>$ but for example $</ 1>$

S3: $<1>$ because $</ 1>$ in Portugal that's like that when they now that s erasmus and they are like ooohhh like super comprehensive don't wanna show a bad image of them so I think if you just start an email dear professor I'm an erasmus student blah blah blah $<2>$ everything is better $</ 2>$

Furthermore, they are often complimented on their ability to use technology, especially the older professors. This is not the case in their home countries.

Example 27:

S4: yeah another thing professors know how to use technology i have like it's she's not really old but she's older around in her sixties I think and she uses moodle like every day and during her class she opens a Word document and she types and then she sends it to moodle so we could have everything we talked about in class

As far as their academic performance is concerned, students were asked to consider and explain whether their knowledge had improved. There was a mixed response amongst interviewees. Some students felt that their abilities have significantly increased, while others considered nothing to have changed.

Example 28:

S2: okay aaaa i academically i learn how to write papers@@@ cause I have never done that in Spain

Example 29:

S4: $<1>$ and academically $\mathrm{i}</ 1>$ learned a lot in computers science because computer science here is much better in vuaxxx better organized than it is in rijeka so learned to program better

Example 30:

S3: at uni it didn't change

\section{Conclusion}

The present study set out to describe prevailing attitudes in informal spoken conversations among Erasmus students at a university in Austria. The general impression obtained from the interviews was that international students are satisfied with their year abroad and they benefit from their experience.

Regarding the use of English, this study has shown that a greater number of Erasmus students were not confronted with any problems in interaction with other non-native speakers, while only a minority reported slight problems with pronunciation. In contrast to Penz's (2015) findings, this research found a handful of instances in which participants complained about different varieties of English (Australian English, Southern American English) and paired with this, an issue with understandability.

It should also be mentioned that according to students' opinions, reasons for the low proficiency of English might correlate with the context. Furthermore, a general 
observation was that Erasmus students expected English to be spoken more around the city, especially for matters involving city administration and public services.

In respect of the academic environment, the research has shown that the majority of international students often encountered problems related to organization of the courses and exams as these practices were different from those in their own countries. Nevertheless, a small number of Erasmus students emphasized the redeeming quality of classes and interaction in the classroom.

A consistent theme in this study is the nature of the relationship between students and professors. Most participants in the study defined this relationship as friendly. Furthermore, one can infer from the data that professors are eager to assist the students with their academic concerns. Another topic is the academic performance of Erasmus students; some participants argued in favour of a noticeable change in their skills, while others believed nothing to have changed.

The current study analyzed only a small sample of Erasmus students. Given the increasing number of international students who migrate to other countries for short stays from several months to a year or a little longer, it would be interesting to compare experiences of individuals at institutions in other parts of the world. Further research regarding the role of ELF in these communities of practice is needed.

\section{References}

Björkman, B. (2011). English as a lingua franca in higher education: Implications for EAP. Ibérica: Revista de la Asociación Europea de Lenguas para Fines Específicos (AELFE), 22, 79-100.

Björkman, B. (2013). English as an academic lingua franca: An investigation of form and communicative effectiveness (Vol. 3). Berlin, Germany: Walter de Gruyter.

Coleman, J. A. (2006). English-medium teaching in European higher education. Language teaching, 39(1), 1-14.

Ferguson, G. (2007). The global spread of English, scientific communication and ESP: questions of equity, access and domain loss. Ibérica: Revista de la Asociación Europea de Lenguas para Fines Especificos (AELFE), 13, 7-38.

Findlay, A. M. (2011). An assessment of supply and demand-side theorizations of international student mobility. International Migration, 49(2), 162-190.

Graddol, D. (2006). English next (Vol. 62). London, UK: British Council.

Jenkins, J. (2000). The phonology of English as an international language. Oxford, UK: Oxford University Press.

Jokić, N. (2017). Metadiscourse in ELF spoken discourse of Erasmus students in Austria. AAA: Arbeiten aus Anglistik und Amerikanistik, 211-223.

Mauranen, A. (2007). Hybrid voices: English as the lingua franca of academics. In K. Flottum (Ed.), Language and Discipline Perspectives on Academic Discourse (pp. 243-59). Newcastle, UK: Cambridge Scholars Publishing.

Mauranen, A. (2010). Features of English as a lingua franca in academia. Helsinki English Studies, 6, 6-28.

Mauranen, A., \& Ranta, E. (Eds.). (2009). English as a lingua franca: Studies and findings. Newcastle upon Tyne, UK: Cambridge Scholars Publishing. 
Penz, H. (2015). English Is Not Enough - Local and Global Languages in International Student Mobility: A Case Study of the Austrian University Context. In A. H. Fabricius \& B. Preisler (Eds.), Transcultural Interaction and Linguistic Diversity in Higher Education (pp. 56-91). London, UK: Palgrave Macmillan.

Seidlhofer, B. (2011). Understanding English as a Lingua Franca. Oxford, UK: Oxford University Press.

Smit, U. (2010). English as a lingua franca in higher education: A longitudinal study of classroom discourse (Vol. 2). Berlin, Germany: Walter de Gruyter.

Truchot C. (2002). Key Aspects of the Use of English in Europe. Retrieved from website: https://rm.coe.int/key-aspects-of-the-use-of-english-in-europe/1680887835

\section{Appendix A. Interview questions:}

1. Why did you choose Austria for your semester/year abroad?

2. Do you like it here? Are there any aspects that you do not like?

3. What do you like most in Austria?

4. Do you like the people here? How are they different from people in your home country? Find three words that best describe Austrians.

5. Are there any habits that you find unusual/ strange in Austria?

6. Did you have negative experiences in Austria?

7. When it comes to universities, how is a university in Austria different from your home university?

8. What about the relationship between students and professors?

9. What do you miss most from your home country?

10. Did you experience culture shock when you came here? Did you adapt? What can a person do in such circumstances? How can you cope with transition?

11. What did you learn from your stay here?

12. Could you live in Austria? Why/why not?

13. What do you think about the English language being used among Erasmus students? Is it easy for you to understand all students?

\section{Copyrights}

Copyright for this article is retained by the author(s), with first publication rights granted to the Journal.

This is an open-access article distributed under the terms and conditions of the Creative Commons Attribution license (CC BY-NC-ND) (http://creativecommons.org/licenses/by-nc-nd/4.0/). 